\title{
REM-BEKAS (REVOLUSI MENTAL BERBASIS KONSELING SPRITUAL TEISTIK): Upaya Membangun Generasi Berkarakter FAST (Fathonah, Amanah, Siddiq, dan Tabligh)
}

\author{
Darimis \\ Program Studi Bimbingan dan Konseling, Jurusan Tarbiyah, Sekolah Tinggi Agama Islam Batusangkar. \\ Korespondensi: Perum Bintang Rizano Regency Blok C.5 Balai Labuah Ateh, Limakaum, \\ Batusangkar, Sumatera Barat \\ e-mail: darimis.uptlbk@gmail.com
}

\begin{abstract}
It is a fact that good values as well as Islamic velues are dicreased in the recent year. It could be caused by several reasons such as the act of amoral and anarchis. In order to overcome this problem, wholistical approach could be used. One of the approaches is using spiritual teistic counselling. This approach is based on Islamic values which derived from prophetic character. It developes one's natural tendency (fitrah), critical thinking, and attitude in parallel with Islamic value. The use of this approach produces good character generation who own FAST character (fatonah- smart, amanah-reliable, siddiq-true, and tabligh-deliver).
\end{abstract}

Kata kunci: revolusi mental, konseling spritual teistik, karakter FAST.

\section{PENDAHULUAN}

$\mathrm{B}$ angsa Indonesia semenjak dahulu merupakan bangsa yang menjunjung tinggi nilai-nilai luhur dan kebaikan. Seperti nilai sopan santun, etos kerja, gotong royong, tolong menolong, kerja sama, kepedulian, dan kesetiakawanan sosial. Semenjak masuknya Islam ke Nusantara nilai-nilai luhur tesebut mengalami penyempurnaan dan penyesuaian dengan Islam, karena menurut Amin Rais (2007: 20) "Umat Islam mempunyai dua kesetiaan, yaitu kesetiaan pada tanah air bangsa dan negaranya dan kesetiaan pada Islam sebagai Diennya." Kesetiaan tersebut menjadikan umat Islam tidak saja mengadopsi nilai-nilai luhur bangsa tetapi mengamalkan nilai-nilai Islam sebagai agamanya.

Nilai-nilai Islam dan keindonesiaan tersebut diaplikasikan, mempribadi, sekaligus menjadi identitas umat
Islam Indonesia. Berkat nilai-nilai tersebut, bangsa Indonesia mampu mengusir penjajah Portugis, Belanda, dan Jepang di bumi Indonesia. Tokoh-tokoh nasional baik Sutan Syahril, Muhammad Hatta, Soekarno, sampai Muhammad Yamin berhasil merumuskan butir-butir Pancasila sebagai dasar Negara Indonesia, merupakan bentuk keberhasilan tokoh bangsa dalam menggali dan mengaktualisasikan nilai-nilai Islam dan budaya Indonesia. Hal ini patut diapresiasi, dihargai, dan dijadikan motivasi untuk meraih peradaban dan bangsa yang bermartabat.

Keberhasilan tokoh bangsa tersebut tidak berbanding lurus dengan kualitas mentalitas sebagian anak bangsa. Nilai-nilai Islam sebagai modalitas bangsa didistorsi oleh penjajah, sehingga ada sebagian anak bangsa mewarisi sikap mental penjajah, kemudian menjadi ciri-ciri karakter manusia Indonesia. Hal 
ini dikemukakan Mochtar Lubis (2007: 123) "Ciri-ciri karakter manusia Indonesia warisan penjajah adalah munafik, enggan bertanggung jawab, berjiwa foedal, percaya tahayul, artistic, berwatak lemah (cengeng), tidak hemat, kurang gigih, serta tidak terbiasa bekerja keras". Pendapat ini tentu tidak sepenuhnya dapat dibenarkan, karena masih ada sebagian rakyat Indonesia yang berprestasi, hebat, dan mampu mengharumkan bangsa Indonesia.

Di samping sikap mental penjajah, nilai-nilai Islam Nusantara semakin tergerus oleh derasnya arus globalisasi, yang ditandai dengan kemajuan teknologi dan komunikasi. Menurut Qadri Azizy (2008: 22) "Globalisasi sebagai ideologi berbenturan dengan nilai Islam, dan mengancam budaya lokal, karena kebanyakan orang sangat dipengaruhi pergaulan, mentalitas, dan pola hidup global yang hedonis." Akibatnya menurut penulis terjadi krisis multidimensi, mulai krisis moral, krisis politik, krisis, ekonomi, krisis kredibilitas, krisis karakter dan jati diri. Kondisi ini disinyalir oleh M. Takdir Ilahi (2014: 18) bahwa "Krisis yang dialami bangsa Indonesia tidak hanya krisis ekonomi maupun politik, tetapi lebih dari itu. Bangsa Indonesia tengah menghadapi krisis karakter atau jati diri yang menjadi landasan fundamental bagi pembangunan karakter bangsa (nation character building)." Aneka kejadian disiarkan TV dan media cetak, mulai dari amuk massa, tawuran, huru hara, ketimpangan, kesewenangan, pergaulan bebas, hilangnya tata karma, nyawa tidak berharga, korupsi, perilaku bullying, aborsi, dan narkoba. Semua itu menunjukkan betapa bangsa Indonesia tengah menghadapi degradasi jati diri dan menurunkan martabat bangsa yang adil beradab.

Krisis karakter terjadi hampir di semua elemen bangsa, sebagaimana dikemukakan Takdir Ilahi (2019) "Krisis karakter terjadi disebabkan karena ke- rusakan individu-individu masyarakat secara kolektif, mulai dari mentalitas penegak hukum, politisi, pelaku usaha, akademisi, birokrat, pejabat negara, sampai masyarakat awam". Hal ini mendeskripsikan bahwa krisis karakter terjadi hampir semua kalangan, misalnya terdengar keputusan diskriminatif yang dibuat oknum hakim terhadap rakyat bawah, lobi-lobi untuk kepentingan kelompok yang dilakukan seorang politisi, tindakan menyuap aparat pemerintah oleh pengusaha, korupsi, kolusi, dan nepotisme dan lain sebagainya merupakan contoh-contoh mentalitas kurang baik".

Mentalitas negatif di atas, idealnya tidak terjadi di Indonesia, mengingat Indonesia memiliki jumlah umat Islam terbesar tidak saja di Asia tetapi di dunia. Umat Islam punya modal menjadi pionir kemajuan karakter, dan mencapai ketinggian peradaban dunia, karena Islam sarat dengan nilai-nilai spritualreligius tidak saja untuk pembentukan karakter, tetapi untuk mewujudkan kembali status sebagai khairu ummah (Umat Terbaik) sebagaimana yang termaktub dalam al-Qur'an surat Al-Imran 110:

Kamu (Umat Islam) adalah umat terbaik yang dilahirkan untuk manusia, (karena kamu) menyuruh (berbuat) yang ma'ruf, dan mencegah dari yang mungkar, dan beriman kepada Allah. Sekiranya Ahli Kitab beriman, tentulah itu lebih baik bagi mereka. Di antara mereka ada yang beriman, namun kebanyakan mereka adalah orang-orang fasik.

Status khairu ummah menurut penulis adalah generasi emas yang berkarakter FAST (fathnah, amanah, siddiq, dan tabligh), generasi cepat dan tangkas, cerdas, cinta Islam, mampu mengadopsi dan merealisasikan sifat-sifat nabi pada semua gerak langkah dalam hidup sehari-hari, yaitu sifat fathanah, amanah, siddiq, dan tabligh. Generasi yang mau serta mampu membela Islam dan mar- 
tabat bangsa, bukan generasi lamban, hedonis, gila kekuasaan dan jabatan politik, suka menonjolkan egosentris dan emosi yang meledak-ledak, sehingga terjebak pada perilaku anarkis, jahat, kriminalitas, yang merugikan bangsa sekaligus dirinya sendiri.

Berdasarkan latar belakang di atas, maka disusun tulisan ini dengan tujuan memberikan alternatif solusi terhadap krisis karakter bangsa ini melalui kajian teoritis dan aplikatif revolusi mental berbasis model konseling spiritual teistik. Pertanyaaan mendasar dalam tulisan ini adalah bagaimana upaya membangun generasi berkarakter FAST (fathanah, amanah, siddiq, dan tabligh) dalam rangka mewujudkan revolusi mental berbasis Model Konseling spiritual tesitik? Tulisan ini berisi analisis konsep dan aplikatif berbagai aspek yang ada pada ruang lingkup, yaitu: 1) Hakikat revolusi mental, yaitu pengertian, dan strategi revolusi mental; 2) konseling spiritual teistik, mulai dari pengertian, peran konseli, dan teknik-teknik konseling; dan 3) profil generasi berkarakter FAST (fathanah, amanah, siddiq, dan tabligh).

\section{HAKIKAT REVOLUSI MENTAL}

\section{Pengertian Revolusi Mental}

Istilah revolusi mental merupakan gabungan dari kata revolusi dan mental. Istilah ini booming" semenjak kampanye Presiden Joko Widodo dan Yusuf Kalla sebagai calon presiden. Kemudian revolusi mental menjadi agenda kabinet kerja Jokowi Yusuf Kalla. Joko Widodo (dalam Indra K. Muhtadi, 2014: 3) mengungkapkan:

Reformasi yang dilaksanakan di Indonesia sejak tumbangnya rezim Orde Baru Soeharto tahun 1998 baru sebatas melakukan perombakan yang sifatnya institusional. Ia belum menyentuh paradigma, mindset, atau budaya politik kita dalam rangka pembangunan bangsa (nation building). Agar perubahan benar-benar bermakna dan berkesinambungan, dan sesuai dengan cita-cita Proklamasi Indonesia yang merdeka, adil, dan makmur, kita perlu melakukan revolusi mental.

Kata revolusi yang dihubungkan dengan mental menjadi revolusi mental. Revolusi dalam bahasa Arab adalah tsaurah yang makna akar katanya berarti menghamburkan debu. Hal ini berarti bahwa revolusi adalah perubahan fundamental dalam tata kehidupan guna membangun peradaban baru dalam aspek social, ekonomi, politik, hukum, kebudayaan, sain dan teknologi, serta keagamaan. (Musa Asya'arie, 2005: xi). Kemudian kata mental berasal dari Bahasa Yunani, memiliki pengertian sama dengan psyche (artinya psikis, jiwa atau kejiwan). Mental diartikan oleh Karlina Supelli sebagai "nama bagi genangan segala sesuatu menyangkut cara hidup. Di dalam cara hidup ada cara berpikir, cara memandang masalah, cara merasa, mempercayai/meyakini, dan cara berperilaku dan bertindak". Hal ini berarti bahwa mental bukan hanya persoalan psikis, namun mengacu pada ranah yang sangat komplek pada diri manusia, baik cara berpikir, cara memahami diri dan dunia, maupun cara menampilkan diri dan kepercayaan yang mereka yakini, cara berpakaian, bertutur kata, berperilaku, dan bertindak.

Sebenarnya istilah revolusi mental diperkenalkan pertama kali oleh Frederick Winslow Taylor lahir tahun 1856, di Amerika. Dia menegaskan bahwa "manajemen ilmiah tidak ada dan tidak bisa tercapai jika tidak terjadi revolusi mental yang lengkap pada prospek pengusaha, tugas-tugas mereka terhadap diri mereka sendiri dan terhadap karyawan mereka". (Agustinus Daniel, 2014: 81). 
Karlina Supelli (2014) juga mengemukakan "Revolusi mental mengarah pada transformasi besar yang menyangkut corak cara berpikir, cara merasa, dan cara bertindak. Kata kunci revolusi mental sebagai strategi kebudayaan adalah menempatkkan arti dan pengertian kebudayaan ke tataran praktek hidup sehari-hari." Pendapat ini menyatakan bahwa revolusi mental tidak cukup dengan perbaikan pola pikir, rasa, dan tindakan saja tetapi jauh dari itu, revolusi mental perlu menempatkan kebudayaan tentang pola pikir, rasa, tindakan dalam praktek hidup sehari-hari.

Menurut L.W Nelson (2006) "Mental revolution is a real movement which should be a source of strength for changes in everyday life." (Revolusi mental adalah gerakan nyata yang seharusnya menjadi sumber kekuatan bagi perubahan dalam hidup sehari-hari). Selanjutnya revolusi mental menurut Agustinus Daniel (2014: 81) "Mental revolution is basically 'back to God' movement, turned back and rely on God to change the old person in us to a new person. So, revolution the real power that will transformation each of us into a new person is not from our own efforts and strength, but from the power and grace of God.

Kutipan di atas artinya revolusi mental adalah 'kembali kepada Allah' yang bertujuan untuk membangun peradaban baru yang lebih baik. Jadi, hakikat revolusi mental adalah proses kembali kepada Allah SWT dan hidup sesuai dengan petunjuk yang diberikan Allah kepada manusia dengan semangat baru yang kaya dengan nilai-nilai spritual, dalam hal ini dicontohkan oleh Nabi Muhammad SAW dengan sifatsifatnya yang terakumulasi dalam akhlakul karimah. Alqur'an menyatakan dalam Qur'an Surat al-Kalam (68) ayat 4: artinya: "Dan Sesungguhnya kamu benar-benar berbudi pekerti yang agung". Pengertian revolusi mental me- nurut penulis lebih mengacu akhlak terpuji atau akhlakul karimah. Pernyataan ini dikuatkan oleh Agung Fatwa (2008: 10-29) "Itu bukan masalah nasib, tetapi barangkali ada kebiasaan-kebiasan buruk yang masih dipelihara, sehingga membawa masalah dalam hidup, sehingga untuk berhasil lakukan pendobrakan terhadap pribadi dan pendobrakan pada lingkungan sosial".

\section{Strategi Revolusi Mental}

Revolusi mental akan sia-sia kalau hanya berhenti pada tataran konsep, atau sekadar inspirasi dokumentasi. Revolusi mental adalah gerakan nyata yang seharusnya menjadi sumber kekuatan bagi perubahan dalam hidup sehari-hari. Jadi Inti revolusi mental menurut penulis adalah akhlak terpuji. Pilihan ini dikuatkan oleh Agung Fatwa (2008: 221) "gerakan revolusi akhlak perlu segera digaungkan, seperti ketika Rasulullah SAW diutus Allah membuat revolusi terbesar dan termulia, dengan memperbaiki akhlak manusia. Kenapa akhlak menurut Marzuki (2015: 14) "Akhlak dalam Islam memiliki hubungan yang sangat erat dengan aqidah syariah, bahkan merupakan satu kesatuan yang tidak dapat dipisah-pisahkan, sebab aqidah, syariah, dan akhlak menjadi kerangka dasar Islam, dan ketiganya harus terintegrasi dan bersinergi dalam diri muslim".

Menurut hemat penulis, untuk mewujudkan akhlak terpuji perlu dilakukan secara komprehensif dan berkesinambungan oleh seluruh elemen bangsa. Karlina Supelli mengungkapkan bahwa "revolusi mental menyentuh dua dimensi sekaligus, yaitu dimensi pola pikir (mind set) dan tatanan sosial masyarakat". Strategi revolusi mental dalam bentuk yang berbeda dijelaskan oleh Agustinus Daniel (2014: 91) "There are three strategies in the mental revolution: 1) awareness; 2) turning point conversion; 3) new vision of life." Artinya ada tiga 
strategi revolusi mental, yaitu: kesadaran, menghidupkan poin pertobatan, dan memperbaharui visi hidup. Strategi revolusi mental yang ditawarkan oleh Agustinus ini sudah tercakup pada model konseling spiritual teistik. Alasan ini juga yang melatarbelakangi pemilihan model konseling spiritual tesitik sebagai basis revolusi mental untuk mewujudkan generasi berkarakter cerdas.

\section{KONSELING SPRITUAL TEISTIK}

\section{Pengertian dan Tujuan Konseling Spritual Teistik}

Permasalahan mentalitas ini menghendaki pendekatan holistik, dan multi strategi, dengan melibatkan semua elemen bangsa. Sebelum menawarkan alternatif solusi terhadap persoalan mentalitas, perlu didiagnosis atau diidentifikasi secara cermat, sehingga ditemukan akar permasalahan secara tepat, untuk selanjutnya dapat direncanakan prosedur intervensi secara komprehensif. Salah satu pendekatannya adalah konseling spritual teistik. Menurut Syamsu Yusuf (2011: 257) "Konseling spritual teistik adalah proses pemberian bantuan kepada individu supaya memiliki kemampuan untuk mengembangkan fitrahnya sebagai makhluk beragama, berperilaku sesuai dengan nilai-nilai agama, dan mengatasi masalah-masalah kehidupan melalui pemahaman, keyakinan dan praktek-praktek ibadah ritual agama yang dianutnya". Defenisi ini mendeskripsikan bahwa tujuan yang ingin diraih pada konseling spiritual teistik adalah pengembangan fitrah beragama pada diri individu, berpikir, berperasaan, bersikap dan bertindak sesuai nilai agama yang dianutnya. Revolusi mental berbasis konseling spiritual teistik bertujuan membantu konseli memperkuat keyakinan kepada Allah SWT, sehingga dapat berpikir, merasa dan bertindak dalam karidor akhlak terpuji.
Menurut Syamsu Yusuf (2011: 258) tujuan khusus konseling spritual teistik, adalah untuk membantu konseli agar lebih efektif dalam hal berikut:

1. Pengalaman dan pemantapan identitas spritual atau keyakinanya kepada Tuhan;

2. memperoleh bimbingan dan kekuatan dari Tuhan dalam mengatasi masalah dan mengembangkan dirinya;

3. memperoleh dukungan sosial dan emosional;

4. menguji dan memperbaiki keyakinan dan praktek-praktek spritual yang tidak berfungsi dengan baik;

5. menerima tanggung jawab dan memperbaiki kekeliruan sikap dan perilaku yang mementingkan diri sendiri;

6. mengembangkan diri dalam kebenaran dan komitmen terhadap keyakinan, nilai-nilai agama atau spritualnya; dan

7. mengaktualisasikan nilai-nilai keyakinan atau spritualitas keagamaam dalam membangun kehidupan bersama yang sejahtera.

Tujuan konseling spritual teistik sangat relevan untuk melakukan revolusi mental mewujudkan generasi berkarakter FAST (fathanah, amanan, siddiq, dan tabligh). Karakter FAST merupakan kebenaran nilai-nilai yang diaplikasikan Nabi Muhammad SAW, konseli harus yakin dengan nilai-nilai Islam dalam bentuk sifat-sifat kenabian tersebut untuk selanjutnya mampu menginternaslisasikan dan menggaktualisasikan nilai-nilai karakter FAST tersebut dalam membangun diri dan peradaban bangsa yang bermartabat.

\section{Peranan Konseli}

Harapan kepada konseli pada konseling spritual teistik adalah hendaknya konseli memberikan informasi pada konselor tentang dirinya (persepsi tentang dirinya, orang lain, dan lingkunganya). Untuk memperoleh tujuan konseling 
secara efektif maka diharapkan juga konseli menampilkan perannya untuk menjelaskan: a) pemahaman dan keyakinan beragamanya, dan bagaimana keyakinan itu berpengaruh terhadap hidupnya; 2) mengekplorasi tujuan dan aspirasi beragama; dan 3) menggali berbagai sumber tentang nilai-nilai spritual termasuk nilai-nilai akhlak para nabi yang disingkat dengan karakter FAST diatas agar membantu usahanya melakukan peningkatan kapasitas diri sendiri. (Syamsu Yusuf, 2011: 259)

\section{Teknik-teknik Konseling Spritual Teistik}

Pada konseling spiritual teistik, ada beberapa teknik atau intervensi spiritual yang dapat digunakan konselor dalam membantu konseli. Menurut Syamsu Yusuf (2011: 261) ada sepuluh teknik yang dapat digunakan, yaitu: a) do'a konselor (counselor prayer); b) pemberian informasi tentang konsep-konsep spiritual (teaching spritual concept); c) merujuk kepada kitab suci (reference to scripture); d) pengungkapan diri spiritual (spiritual self-diclosure); e) konfrontasi spiritual (spiritual confrontation); penafsiran spiritual (spiritual assessment); f) do'a bersama konselor dan konseli (counselor and conselee prayer); g) dorongan untuk memaafkan (encouragement for forgiveness); $\mathrm{h}$ ) penggunaan komunitas atau kelompok beragama (use of religious community); i) do'a konseli (conselee prayer); dan $\mathrm{j}$ ) biblioterapi keagamaan (religious bibliotherapy).

Semua teknik konseling spiritual di atas dapat diaplikasikan dalam mewujudkan generasi berkarakter FAST, seperti pada table berikut:

Tabel 1

Teknik Konseling Spritual Teistik

\begin{tabular}{|c|c|c|}
\hline $\begin{array}{c}\text { Teknik } \\
\text { Konseling }\end{array}$ & Keterangan & Contoh \\
\hline 1 & 2 & $\mathbf{3}$ \\
\hline 1. Do'a Konselor & $\begin{array}{l}\text { Pembacaan do'a oleh } \\
\text { konselor }\end{array}$ & $\begin{array}{l}\text { Konselor mendo'akan konseli agar dapat } \\
\text { mengembangkan pemahaman tentang nilai-nilai yang } \\
\text { terkandung pada karakter FAST. }\end{array}$ \\
\hline $\begin{array}{ll}\text { 2. } & \text { Pemberian informasi } \\
\text { tentang konsep-konsep } \\
\text { spiritual }\end{array}$ & $\begin{array}{l}\text { Pemberian informasi tentang } \\
\text { isu-isu teologis dan konsep- } \\
\text { konsep spiritual yang terkait } \\
\text { dengan Sifat-sifat Nabi yang } \\
\text { disingkat dengan FAST }\end{array}$ & $\begin{array}{l}\text { Konselor memberikan informasi agar konsel } \\
\text { berkembang kesadaran tentang kebenaran, sikap cinta } \\
\text { kasih dan kedamaian sebagai nilai yang terkandung } \\
\text { dalam Al-Qur'an dan Hadis nabi. Kemudian membantu } \\
\text { konseli agar memandang dirinya berharga, sesua } \\
\text { dengan Firman Allah tentang martabat dirinya, dan akan } \\
\text { lebih meningkat martabatnya jika mampu } \\
\text { mengalikasikan karakter FAST dalam hidup sehari-hari. }\end{array}$ \\
\hline 3. Merujuk pada Kitab Suci & $\begin{array}{l}\text { Membaca kitab suci untuk } \\
\text { memantapkan keyakinan }\end{array}$ & $\begin{array}{l}\text { Konselor bersama konseli membaca dan menelaah ayat- } \\
\text { ayat Allah yang relevan dengan masalah stres traumatis } \\
\text { sehingga dapat mengkonter perasaan yang tidak tepat. }\end{array}$ \\
\hline $\begin{array}{l}\text { 4. Pengungkapan } \\
\text { spritual }\end{array}$ & $\begin{array}{l}\text { Konselor mengungkapkan } \\
\text { pengalaman spritualnya } \\
\text { sendiri dan orang lain untuk } \\
\text { mencoba mempengaruhi } \\
\text { konseli }\end{array}$ & $\begin{array}{l}\text { Konselor berbagi pengalaman spiritual dirinya dan } \\
\text { orang lain, dan mencoba mengemukakan model sebaga } \\
\text { upaya menguatkan konseli mengaktualisasikan karakter } \\
\text { FAST. }\end{array}$ \\
\hline 5. Konfrontasi Spritual & $\begin{array}{l}\text { Mengkonfrontasi } \begin{array}{r}\text { konseli } \\
\text { terkait dengan keyakinan } \\
\text { spritualnya }\end{array} \\
\end{array}$ & $\begin{array}{l}\text { Konselor mengkonfrontasi konseli mengenai } \\
\text { ketidaksuaian antara nilai-nilai agama yang diyakininya } \\
\text { dengan perbuatannya. }\end{array}$ \\
\hline 6. $\quad$ Penaksiran spritual & $\begin{array}{l}\text { Konselor menaksir status } \\
\text { spiritual konseli }\end{array}$ & $\begin{array}{l}\text { Konselor mengidentifikasi sejarah perkembangan } \\
\text { keberagamaan konseli dan menaksir kadar perasaan } \\
\text { konseli dalam hubungan dengan Allah dan Nabi } \\
\text { Muhammad melalui skala penilaian FAST. }\end{array}$ \\
\hline $\begin{array}{l}\text { 7. Do'a bersama konselor } \\
\text { dengan konseli }\end{array}$ & $\begin{array}{l}\text { Do'a bersama konseli dalam } \\
\text { pertemuan konseling }\end{array}$ & $\begin{array}{l}\text { Konselor mengajak konseli berdo'a di awal dan diakhir } \\
\text { konseling untuk memeroleh petunjuk. }\end{array}$ \\
\hline 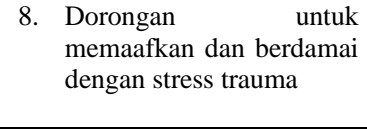 & $\begin{array}{l}\text { Berdiskusi tentang makna } \\
\text { memaafkan dan berdamai } \\
\text { dan mendorongnya untuk } \\
\text { memaafkan diri, orang lain, }\end{array}$ & $\begin{array}{l}\text { Konselor mendiskusikan tentang makna memaafkan } \\
\text { baik terhadap dirinya (rasa bersalah) maupun orang lain } \\
\text { serta menggunakan perbuatan memaafkan itu untuk } \\
\text { memperbaiki hubungan. }\end{array}$ \\
\hline
\end{tabular}




\begin{tabular}{|c|c|c|}
\hline & dan alam & \\
\hline $\begin{array}{ll}\text { 9. } & \text { Penguatan } \\
\text { kelompok }\end{array}$ & $\begin{array}{l}\text { Menggunakan kelompok } \\
\text { beragama sebagai sumber } \\
\text { terapi dari luar }\end{array}$ & $\begin{array}{l}\text { Konselor merujuk kepada ahli agama untuk } \\
\text { membicarakan masalah teologi atau spiritual yang } \\
\text { khusus. }\end{array}$ \\
\hline 10. Bibliotherapi keagamaan & $\begin{array}{ll}\text { Penggunaan } & \text { literature } \\
\text { keagamaan } & \end{array}$ & $\begin{array}{l}\text { Konselor mendorong konseli untuk membaca buku- } \\
\text { buku atau referensi keagamaan yang terkait dengan } \\
\text { mengaktualkan karakter FAST. }\end{array}$ \\
\hline
\end{tabular}

Tabel di atas mendeskripsikan teknik-teknik konseling spiritual teistik yang dapat digunakan konselor lengkap dengan contoh aplikasinya. Menurut Richards dan Bergin dalam Yuliantai (2014) teknik konseling menurut model konseling spiritual teistik bisa dengan ibadah, berdo'a, membahas kosep-konsep spiritual, referensi kitab suci, pengalaman spiritual, konfrontasi spiritual, dorongan memaafkan, penggunaan komunitas agama, dan biblioterapi religious.

\section{PROFIL GENERASI BERKARAK- TER FAST}

Proses konseling mengharapkan terjadinya perubahan yang signifikan pada diri individu, terutama perubahan dari segi kognitif, emotif dan perilaku. Karakter mengacu pada serangkaian sikap dan perilaku untuk melakukan hal yang terbaik. Menurut Battistich dalam Arismantoro (2009: 65) individu yang berkarakter baik adalah seseorang yang berusaha melakukan yang terbaik. Menurut Penulis melakukan yang terbaik artinya berakhlak mulia atau terpuji. Ada sembilan karakter dasar (Ratna Megawangi, 2004:96) yang di dalamnya terkandung nilai-nilai universal, yaitu sebagai berikkut:

1) Cinta tuhan dan segenap ciptaanNya; 2) Kemandirian dan tanggung jawab; 3) Kejujuran/amanah, kebijaksanaan; 4) Hormat dan santun; 5) Dermawan, suka menolong dan gotong royong; 6) Percaya diri, kreatif, dan pekerja keras; 7) Kepemimpinan dan keadilan; 8) Baik dan rendah hati; dan 9) Toleransi dan kedamaian dan kesatuan.
Kesembilan karakter dasar di atas telah sesuai dengan Islam Nusantara yang menempatkan kecintaan kapada Tuhan dan alam semesta sebagai substansi dasar ideologi Pancasila. Sembilan karakter dasar tersebut terdapat dalam Islam, sudah terhimpun dalam sifat-sifat kenabian, seperti yang diaktualisasikan Nabi Muhammad SAW, yaitu siddiq, amanah, fathanah, dan tabligh. Pada tulisan ini disusun akronim FAST (fathanah, amanah, siddiq, dan tabligh), untuk memudahkan mengingat, membuat kesan emosional, sehingga bertahan lama di memori pembaca. Berikut diuraikan karakter FAST yang dimaksudkan secara lebih detail.

\section{Fathanah}

Fathanah berarti kecerdasan, lawan dari jahlun (bodoh). Kecerdasan menjadi indikator keberhasilan individu dalam kehidupan. Fathanah diartikan dengan kecerdasan, kemahiran, atau penguasaan terhadap bidang tertentu. Kecerdasan merupakam kemampuan berpikir lebih cepat, menyelesaikan masalah lebih mudah, dan mengatasi kesulitan lebih jitu dibandingkan dengan individu lain. Menurut Toto Tasmara (2001: 212) "Fathanah merupakan kecerdasan yang mencakup kecerdasan intelektual, emosional, dan terutama spiritual".

Pandangan Abdul Malik (2013: 197) Individu fathanah tidak saja menguasai bidang ilmunya, tetapi juga memiliki dimensi ruhani yang kuat. Tidak saja cerdas tetapi juga memiliki kebijaksanaan dan kearifan dalam berpikir dan bentindak. Fathanah menjadi kecerdasan total yang berawal dari ketajaman intusi mata batin (basirah) 
yang berada pada dimensi ruhani. Beberapa karakteristik pribadi fathanah menurut Toto Tasmara (2001:213) adalah sebagai berikut:

a. The man of wisdom. Terampil melaksanakan profesinya, sangat berdedikasi dan dibekali dengan hikmah dan kebijaksanaan;

b. High in integrity. Bersungguh-sungguh dalam segala hal, mampu melihat dibalik tampak dengan perenungan dan tafakur;

c. Willingness to learn. Memiliki motivasi yang sangat kuat untuk terus belajar dan mampu mengambil pelajaran dari setiap peristiwa yang dihadapi;

d. Proactive stance. Proaktif dan ingin memberikan kontribusi positif bagi lingkungan

e. Fait in God. Sangat mencintai Tuhannya, dan kerena selalu mendapat petunjuk dari-Nya;

f. Creditable and refutable. Menempatkan diri sebagai insane yang dapat dipercaya;

g. Being the best. Selalu ingin menjadikan dirinya sebagai teladan, dengan menampilkan unjuk kerja yang terbaik;

h. Empathy and compassion. Menaruh cinta kepada orang lain sebagaimana ia mencintai dirinya sendiri;

i. Emotional maturity. Memiliki kedewasaan emosi, tabah, dan tidak pernah mengenal menyerah serta mampu mengendalikan diri;

j. Balance. Memiliki jiwa yang tenang;

k. Sense of mission. Memiliki arah tujuan dan arah yang jelas dalam kehidupan;

1. Sense of competition. Memiliki sikap untuk bersaing secara sehat.

\section{Amanah}

Amanah artinya benar-benar bisa dipercaya. Individu yang amanah selalu ingin menampilkan sikap dan perilaku bisa dipercaya, menghormati dan di- hormati. Menurut Toto Tasmara (2001: 221) Amanah merupakan kekuatan ruhani yang senantiasa diterima dengan penuh rasa percaya, dihormati dan dipercaya. Karakteristik individu memiki sifat amanah adalah:

a. Rasa tanggung jawab. Ingin menunjukkan hasil optimal dan islah;

b. Kecanduan kepentingan. Merasakan hidup memiliki nilai, dan ada seuatu yang penting, dikejar dan mengejar sesuatu agar dapat menyelesaikan amanah dengan sebaik-baiknya;

c. Al-amin. Ingin dipercaya dan mempercayai;

d. Honorable. Hormat dan dihormati

\section{Siddiq}

Siddiq diartikan dengan jujur. Kejujuran merupakan komponen ruhani yang memantulkan berbagai sikap terpuji. Individu jujur adalah individu yang berani menyatakan sikap secara transparan, terbebas dari segala kepalsuan dan penipuan. Siddiq dibagi oleh Toto Tasmara (2004: 192) menjadi tiga bagian, yaitu jujur pada diri sendiri, jujur pada orang lain, dan jujur pada Allah SWT.

Menurut Marzuki (2015: 98) Jujur pada diri sendiri yaitu berpihak pada kebenaran. Indikator orang yang jujur pada diri sendiri yaitu, berjalan dengan penuh keyakinan diri, berdiri di atas kebenaran, mandiri, memiliki kesadaran otentik, dan berani mempertahankan makna hidup dan jati dirinya bertanggung jawab, disiplin, dan taat. Selanjutnya jujur pada orang lain bukan hanya sekadar berkata dan berbuat benar, namun berusaha memberikan manfaat sebesar-besarnya bagi orang lain. Terakhir jujur pada Allah SWT, artinya berbuat dan memberikan segala-galanya untuk Allah, atau beribadah hanya untuk Allah 


\section{Tabligh}

Tabligh artinya menyampaikan kebenaran melalui suri teladan dan perasaan cinta yang sangat mendalam. Ditegaskan oleh Marzuki (2015: 97) "Rasulullah adalah komunikator unggul disertai pesan-pesan tidak saja verbal belaka, tetapi diikuti gerak amal nyata. Nilai-nilai tabligh memberikan muatan yang mencakup aspek kemampuan ber- komunikasi, kepemimpinan, pengembangan dan peningkatan kualitas sumber daya insani, dan kemampuan diri untuk mengelola sesuatu.

Indikator atau ciri-ciri karakter FAST secara nyata dapat dilihat dari perilaku individu sehari-hari, dengan membuat indikator penampilannya dengan memperhatikan akhlakul karimah seperti tabel di bawah ini:

Tabel 2

Indikator Penampilan Karakter FAST

\begin{tabular}{llll}
\hline FATHANAH & AMANAH & SIDDIQ & TABLIGH \\
\hline Kecerdasan & Prinsip & Jujur & Komunikatif \\
Berilmu & Harmoni & Tawadhu' & Empati \\
Etika & Cinta & Loyal & Proaktif \\
Profesional & Respek & Sabar & Memimpin \\
Realistis & Tanggung jawab & Ikhlas & Spontanitas \\
Rasional & Tepat janji & Transparan & Bijaksana \\
Inisiatif & Misi & Perbaikan & Melayani \\
Solusi & Tugas & Mandiri & Kerjasama \\
Inovasi & Kehormatan & Adil & Dukungan \\
Prestasi & Visioner & Terbuka & Teladan \\
Kreativitas & & Teladan & \\
Toleransi & & Objektif & \\
Wisdom & & & \\
Analitis & & & \\
Toleransi & & & \\
\hline
\end{tabular}

Kandungan akhlak mulia yang terdapat pada pada untaian kata atau akronim FAST, kiranya dapat menjadi pedoman bersikap dan bertingkah laku sebagai bentuk ideal, sekaligus sebagai bahan renungan serta pembiasaan, sehingga ruhani individu semakin tajam dan sensitif menghadapi tantangan dalam cara berperan di tengah-tengah masyarakat sesuai dengan nilai-nilai Islam.

\section{PENUTUP}

Revolusi mental yaitu ikthtiar untuk melakukan perbaikan pola pikir, rasa, dan tindakan dan pola pikir, rasa, dan tidakan tersebut diaplikasikan dalam praktek hidup sehari-hari, menjadi kebiasaan, dan pada akhirnya menjadi kepribadian.

Banyak pendekatan yang dapat digunakan, salah satunya adalah model konseling spiritual teistik, berfokus pada nilai-nilai religius Islam untuk mengembangkan fitrah, berpikir, berperasaan, bersikap dan bertindak individu sesuai nilai-nilai Islam demi mewujudkan generasi yang berkarakter FAST (fathanah, amanah, siddiq, dan tabligh), sebagai sifat para nabi, terutama nabi Muhammad SAW. 


\section{DAFTAR RUJUKAN}

Asy'arie, Musa. 2005. Islam di Tepian Revolusi: Ideologi Pemikiran dan Gerakan. Yogyakarta: Pilar Media.

Abdul Malik. 2014. Peningkatan Keteladanan Akhlak Mulia. Semarang: Unes Press

Arismantoro. 2008. Tinjauan Berbagai Aspek Character Building: Bagaimana Mendidik Anak Berkarakter. Yogyakarta: Tiara Wacana.

Azizy, A.Qadri. 2008. Melawan Globalisasi: Reinterpretasi Ajaran Islam. Yogyakarta: Pustaka Pelajar

Daniel, Agustinus. 2015. Mental Revoluition: A Small Change for A Better Civilization. (Online) (http://www.smashwords.com/boo ks/download/485778/1/latest/0/0/m ental-revolution-a-small-changefor-a-better-civilization-free.pdf. Diakses 13 April 2015).

Lubis, Mochtar. 2007. Manusia Indonesia: sebuah Pertanggungjawaban. Jakarta: Idayu Press.

Marzuki. 2015. Pendidikan Karakter Islam. Jakarta: Amzah.

Muhtadi, Indra K. 2014. Revolusi Mental. Jakarta: Rineka Cipta.

Nelson, L.W. 2006. A Mental Revolution. Journals in The Northwest. (online), (https://ohiostatepress.org/Books/B ook\%20Pages/Nelson\%20.Mental. $\underline{\mathrm{html}}$, diakses

Megawangi, Ratna. 2004. Pendidikan Karakter Solusi yang Tepat untuk Membangun Bangsa. Jakarta: Star Energi.

Rais, Amin. 2007. Cakrawala Islam antara Cita dan Fakta. Bandung: Mizan

Supelli, Karlina. 2014. Mengartikan Revolusi Mental. (online), (http:// http://www.kaskus.co.id/thread/53 ace47d12e257c71b8b45b3/antropo log-ui-mengartikan-revolusimental/. Diakses 15 April 2015)

Takdir Ilahi, Mohammad. 2014. Gagalnya Pendidikan Karakter: Analisis dan Solusi Pengendalian Karakter Emas Anak Didik. Yogyakarta: ArRuzz Media.

Yusuf LN, Syamsu. 2011. Konseling Spritual Teistik. Dalam Suherman dan Nadang Budiman (Eds), Pendidikan dalam Perspektif Bimbingan dan Konseling (hlm.239270). Bandung: UPI Press.

Yulianti. 2013. Pendekatan Cultural Spritual dalam Konseling Bagi Lansia. Jurnal Psikologi. (online), (https://bkpemula.files.wordpress.c om/.../18-yulianti-pendekatanspiritual. fdf.html.diakses tanggal 15 April 2015).

Tasmara, Toto. 2001. Kecerdasan Ruhaniah (Trancendental Intellegence). Bandung: Gema Insani Press. 